\title{
Dynamic Evaluation and Spatial Distribution Characteristics of Agricultural Green Development Level in Restricted Development Areas: a Case Study of Yili River Valley, China
}

\author{
Guiling Wang ${ }^{1}$, Degang Yang $^{2}$, Chuanhe Xiong ${ }^{3 *}$ \\ ${ }^{1}$ School of Geographic Science, Nantong University, Nantong 226007, China \\ ${ }^{2}$ Xinjiang Institute of Ecology and Geography, Chinese Academy of Sciences, Urumqi 830011, China \\ ${ }^{3}$ Key Laboratory of Watershed Geographic Sciences, Nanjing Institute of Geography \& Limnology, \\ Chinese Academy of Sciences, Nanjing 210008, China
}

Received: 9 October 2020

Accepted: 18 December 2020

\begin{abstract}
Green development is a new mode to solve the contradiction between agricultural development and ecological protection in the new era. It is very urgent to improve agricultural green development level of the restricted development zones because of its special status in safeguarding national agricultural products and ecological security for countries worldwide. From a new perspective of agroecosystem symbiosis, this study makes dynamic comparative analysis of agricultural green development level between 2013 and 2018 by constructing multi-dimensional evaluation index system from green production, green innovation, green eco-protection and green economy. The results indicated that: (1) on the whole, the agricultural green development level in Yili River Valley shows an upward trend, but that of most counties belong to the low-and medium-level; (2) the spatial heterogeneity of agricultural green development are more obvious, showing the characteristics of high in the northwest and low in the southeast; (3) by clustering analysis with the comprehensive evaluation matrix of green agriculture, there exist three types of agricultural development: "High level-High benefits", "High level-Low benefits" and "Low level-Low benefits", presenting an unbalanced development state. On this basis, according to the existing problems and the advantages for development of Yili River Valley, this study proposed the green empowerment path of agro-ecosystem symbiosis based on protecting ecological chain and promoting value-added chain, which has broad prospects for promotion and application in similar restricted development areas.
\end{abstract}

Keywords: restricted development areas, agricultural green development, spatial differentiation, agro-ecosystem symbiosis, Yili River Valley

*e-mail: chhxiong@niglas.ac.cn 


\section{Introduction}

With the further implementation of the new idea of "coordination, green, open, sharing and sustainability", the unified green development model of "speed, quantity and quality" has become a necessary choice to break through the natural resources and environmental constraints and solve existing problems [1,2]. Therefore, green agriculture which is based on the safety guarantee of the quality of agricultural products can promote the comprehensive development of ecological, economic and social benefits [3,4]. At present, the demand pressure of population on resources and environment is increasing day by day, the sustainable development in agriculture is seriously restricted [5], and the hard constraints of agricultural resources and environment are tightening. Countries all over the world also pay more and more attention to agricultural green innovation and highquality development, which has become the main trend of current agriculture development [6, 7]. Restricted development zones are the areas with weak carrying capacity of resources, poor economic and population conditions and related to national food security, ecological security and homeland security, including key ecological function areas and main agricultural production areas [8]. As a special region, the ecosystem of the restricted development areas is relatively fragile and sensitive, and the contradiction between economic development and environmental protection is particularly prominent, so it is an urgent problem to explore the path of agricultural green development with energy saving, consumption reduction, recycling and efficiency by a scientific way in order to promote coordinated development of agricultural ecology and agricultural economy.

In the early period, foreign scholars have begun to make exploratory research on green agriculture, which provides a lot of valuable reference experience for the related studies in our country, mainly focused on the quantitative evaluation and application of green economy, green agricultural products, green development policy and so on. Under the background of agricultural green transformation, scholars began to pay attention to the quantitative evaluation of green economy in the field of agriculture $[9,10]$. Then, the quantitative evaluation methods of green economy are applied to the construction of agricultural sustainable development evaluation system [11]. For example, Kanter et al. paid attention to the coordination between human development and agricultural production, and constructed an optimization evaluation framework of agricultural sustainable development including agronomy, environment, social economy, diversity of agricultural products, and human nutrition [12]. Quintero-Angel et al. emphasized the comprehensiveness of the evaluation system and constructed the agricultural sustainable development evaluation system from three dimensions of society, economy and ecology [13]. In China, scholars have done more research on the evaluation system of sustainable agriculture. Some researchers quantified the standards of low-carbon agriculture to construct the lowcarbon agriculture evaluation system [14, 15], others constructed the eco-agriculture evaluation system from the comprehensive dimensions of economic efficiency or economic and ecological benefits $[16,17]$. In addition, based on the dimensions of agricultural products, ecological economy, a few scholars established the evaluation system of green agriculture, sustainable development, agricultural ecological civilization [18, 19].

From the perspective of green agricultural products, relevant scholars have studied green agriculture from different aspects, and indicated that green agriculture is an ecological agriculture model with low input to maintain ecological balance and economic potential. The developed countries in Europe and United States have put forward the idea of organic agriculture, which uses a pollution-free, healthy and green operation mode in each link of the production and processing of agricultural products, and adopts a sustainable agricultural production system [20]. Some scholars believed that one of the cores of agricultural green development was technological innovation, which include popularizing new technologies such as watersaving, seed-saving, fertilizer-saving and biochemical to solve the problems of high production cost, nonpoint source pollution, and the quality of agricultural products, and exploring a green agriculture development road of "high-efficiency output + product quality assurance + resource thrift + eco-friendly" [21, 22]; Others have pointed out that it is necessary to guide and establish the consumption trend and habits of green agricultural products in the consumption of agricultural products [23, 24], with emphasis on popularizing the production mode of pollution-free, green and organic agriculture [25]. Additionally, a small number of scholars considered that market demand should be guided, paying attention to the increment of green and high-quality agricultural products and pursuing the diversification, differentiation and branding development of products in order to meet the people's consumption demands for safe, high-quality, nutritious and healthy food $[26,27]$.

From the perspective of green agricultural development policy, foreign countries have established green agriculture information technology websites in earlier times, which can enable farmers to obtain the latest knowledge, technology, market changes and other green agriculture-related information. The researchers also think that promoting wider applications of new agricultural technologies have greatly improved productivity which is the key factor of developing green agriculture [28, 29]. In America, mainly implementing the agricultural policy of "green subsidies" which connects agricultural income with ecological quality, so as to improve farmers' environmental protection awareness [30]. In France, producers and processors of 
green agricultural products must be officially certified by the state to carry out production and operation, and can be offered the preferential subsidies after meeting relevant requirements [31]. Then domestic scholars believed that there are many factors involved in promoting the green and sustainable development of agriculture, and it is very important to coordinate the relationship among economy, society and ecology [32], while others deemed that the realization of green agricultural development needed to adapt to the local conditions, improve the level of machinery [33], production and talent quality [34], and control the agricultural non-point source pollution [35]. Furthermore, a few scholars proposed to promote the development of green industry by means of overall planning, promoting industrial development and restoring ecological environment, so as to take the road of sustainable development [36].

As mentioned above, the majority have focused on single or static evaluation of agricultural green development by taking province or city or county as the research unit, which is lack of regional, spatial and dynamic research. Furthermore, for the restricted development areas, relevant researches mainly focus on regional economic development [37], spatial function subdivision [38], policy guidance [39], benefit compensation mechanism [40], poverty [41], among which economic development studies involve leading industry selection, industrial structure, ecological economy, economy-ecological coupling relationship, etc. However, there are no relevant studies on the green development of agriculture in restricted development areas. Due to involving the security of the country's agricultural products supply and ecological security, and because it is not suitable for large-scale and highintensity industrialization and urbanization to develop with special environment, the contradiction between agricultural development and ecological protection is more prominent. Therefore, it is more important and meaningful to learn how to scientifically explore the coordinated development path of agricultural ecology and agricultural economy from the perspective of dynamic and spatial analysis.

This paper, taking Yili River Valley as a case study, aims to make dynamic comparative analysis of agricultural green development level between 2013 and 2018 , explore the characteristics of spatial distribution and its changing trend, and dissect the causes by the method of comprehensive evaluation matrix of green agriculture, which can provide a scientific basis for path choice of agricultural green development. It points out the importance of improving the agricultural green development level of restricted development areas due to its significance in optimizing the ecological environment and enhancing the comprehensive production capacity of agriculture.

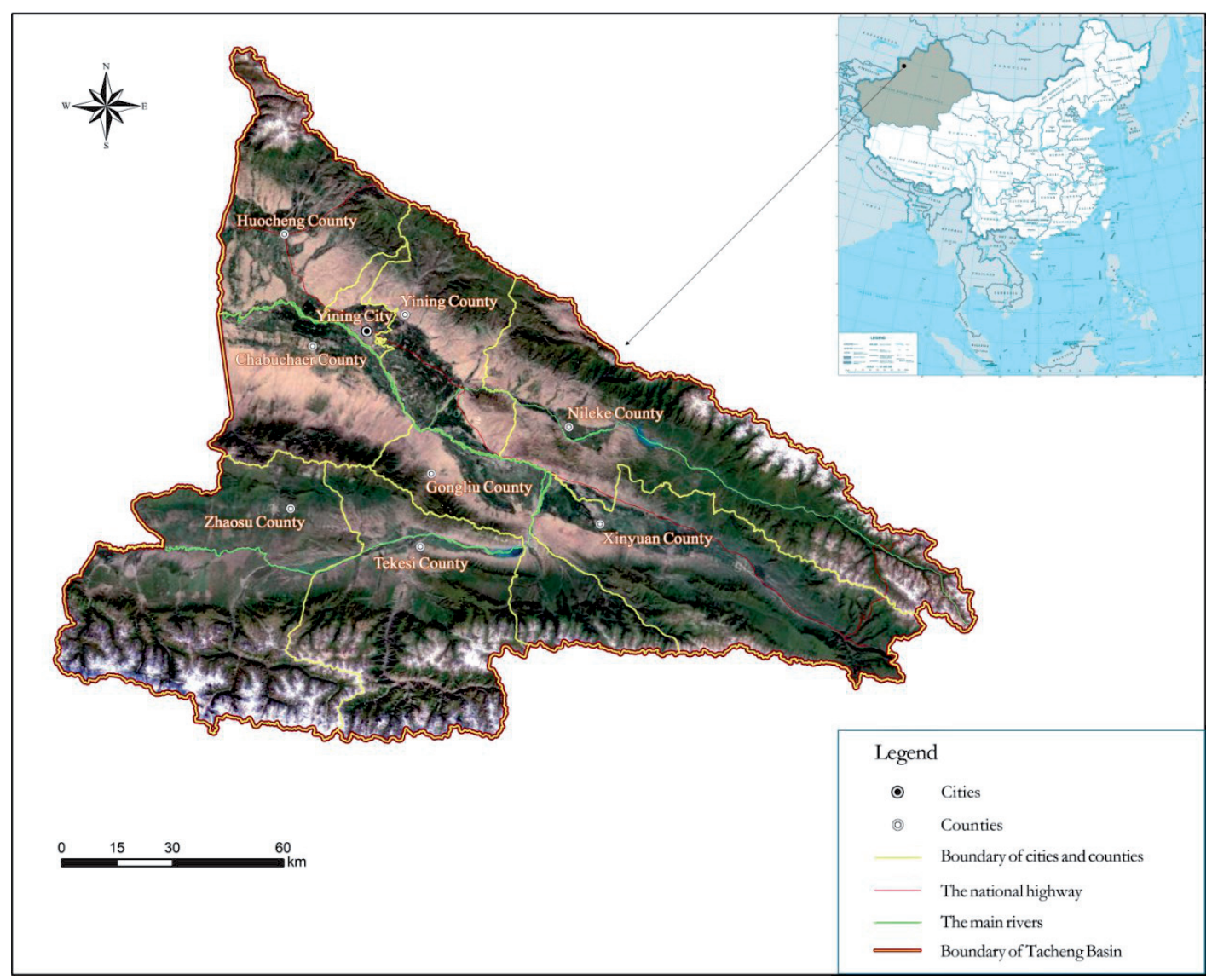

Fig. 1. Location of Yili River Valley. 


\section{Materials and Methods}

\section{Description of Study Area}

Yili River Valley covers one city and eight counties, located in the northwest of Xinjiang Uygur Autonomous region in China, bordering on Kazakhstan in the west (Fig. 1). Its geographical extent is $42^{\circ} 14^{\prime} \mathrm{N}-44^{\circ} 50^{\prime} \mathrm{N}$ and $80^{\circ} 09^{\prime} \mathrm{E}-84^{\circ} 56^{\prime} \mathrm{E}$, and east, south and north is surrounded by mountains, which results in a humid temperate continental climate. This region is an important oasis agricultural area and animal husbandry base in Xinjiang with favorable climatic conditions, rich water and soil resources. In recent years, the modern agricultural development level in Yili River Valley has been constantly improved and its gross agricultural product has increased to 26.68 billion yuan in 2019 . However, unreasonable mode of agricultural production has serious damage to the ecological environment carrying capacity, which largely restricts the further improvement of agricultural production level and agricultural economic benefits.

\section{The Method of Evaluation Index System Construction}

The quantitative analysis of agricultural green development level adopts index evaluation method which mainly considers its comprehensiveness and reference. Comprehensiveness means that the index can evaluate the production, processing and consumption of agricultural green development, so as to better reflect the agricultural green development level; Reference means that the index evaluation results not only reflect the overall level of agricultural green development, but also show the shortcomings of agricultural green development, which has important reference value for policy-making to promote agricultural green development.

Therefore, based on the national policies of green agricultural development, combined with the "Implementation Plan of Green Development Evaluation in Xinjiang Uygur Autonomous Region" and "Implementation Plan of Green Development Evaluation in Yili Prefecture", this paper constructs a multi-dimensional evaluation index system of agricultural green development from a new perspective. The second-level evaluation index system includes four aspects: green production, green innovation, green eco-protection and green economy. Considering the availability of data, this paper selects 20 three-level indicators as the evaluation system of agricultural green development level. The detailed indicators are listed in Table 1.

\section{The Method of the Weighted Average}

The evaluation system of agricultural green development level is all positive indexes, but the value of indexes has been positive and negative. Therefore, to facilitate analysis and comparison, this paper processes the indexes by the method of dimensionless positive change. The formula is as follows:

$$
X_{i j}^{\prime}=\frac{x_{i j}}{\sqrt{\sum_{i=1}^{n} x_{i j}^{2}}}+1
$$

...where $X_{i j}^{\prime}$ is the standardized value of the index. $x_{i j}$ is the original data; $i$ and $j$ is respectively the metrics for each row and each column.

In the measurement methods of the comprehensive index system, the entropy weight method is an objective weight determination that can avoid the interference of subjective factors [42]. This method of analytic hierarchy process calculates the weight of each element by ordering in single level and whole system of each evaluation index and judges the matrix consistency test during the sorting operation to avoid one-sidedness. When the consistency ratio is less than 0.1 , the consistency check of the judgement matrix is acceptable; otherwise, the judgement matrix does not meet the consistency requirement and corresponding judgement matrix must be revised until the results are tested with consistency [43].

Based on the weighted value calculated by the methods of entropy weight and analytic hierarchy process, this paper uses the weighted average method to calculate the comprehensive weight value of each evaluation unit. Based on the related scientific research [44], by consulting the relevant experts in ecology and regional economics, the weight of entropy method and analytic hierarchy process is, respectively, 0.5 and 0.5 , using formula (3) to obtain the final weight of each index.

$$
W=0.5 W_{j} \times 0.5 W_{A H P}
$$

...where $W$ is the final weight of each indicator; $\mathrm{j}$ is the value of each column; $W_{\mathrm{j}}$ is the weight of the entropy method; $W_{\mathrm{AHP}}$ is the weight of the analytic hierarchy process.

\section{The Model of Green Development Index}

Green development index is the comprehensive exponent of the second-level index in that system, which is divided into green production index, green innovation index, green eco-protection index and green economy index in the paper. The formula is as follows:

$$
\mathrm{GDI}_{j}=\sum_{i=1}^{n} W \times X_{i j}^{\prime}
$$


Table 1. Index system of agricultural green development level in Yili River Valley.

\begin{tabular}{|c|c|c|}
\hline The first-level index & The second-level index & The third-level index \\
\hline \multirow{20}{*}{$\begin{array}{l}\text { Agricultural green } \\
\text { development level } \\
\text { (GDI) }\end{array}$} & \multirow{5}{*}{ Green production $(\mathrm{G} 1)$} & The decreased rate of fertilizer application intensity (X1) \\
\hline & & The decreased rate of application intensity of agricultural film (X2) \\
\hline & & Decline rate of pesticide application intensity (X3) \\
\hline & & Agricultural water-saving irrigation area (X4) \\
\hline & & Comprehensive utilization rate of stock raising wastes (X5) \\
\hline & \multirow{5}{*}{ Green innovation (G2) } & The number of computers (X6) \\
\hline & & The internet penetration rate $(\mathrm{X} 7)$ \\
\hline & & The total power of agricultural machinery (X8) \\
\hline & & The leading enterprises of agricultural industrialization (X9) \\
\hline & & Agricultural science and technology demonstration zone area (X10) \\
\hline & \multirow{5}{*}{ Green eco-protection (G3) } & The quantity of green food labeling products (X11) \\
\hline & & The number of green food certification enterprises(X12) \\
\hline & & The decreased rate of foodborne illness (X13) \\
\hline & & The forest coverage rate (X14) \\
\hline & & The wetland protection rate (X15) \\
\hline & \multirow{5}{*}{ Green economy (G4) } & The gross output value of agriculture (X16) \\
\hline & & The per capita GDP growth rate of agriculture(X17) \\
\hline & & The per capita disposable income of villagers (X18) \\
\hline & & The output value of leisure agriculture and rural tourism (X19) \\
\hline & & The proportion of agricultural products processed deeply (X20) \\
\hline
\end{tabular}

Note: a) In order to better reflect the dynamic nature of green agricultural development, some indicators are processed in the form of rate of change; b) The third-level index are all positive; c) The alpha code can be used to represent the name of the index in the paper.

...where $\mathrm{GDI}_{j}$ is the green development index; I is the metrics for each row; $j$ is the metrics of each column; $W$ is the final weight of evaluation index; $X_{i j}^{\prime}$ is the standardized value of the index.

\section{The Method of Comprehensive Evaluation Matrix}

In order to further analyze the regional differences of agricultural green development in Yili River Valley, referring to the research results of relevant scholars (Tian and Zhang, 2013b), this study scientifically constructed the comprehensive evaluation matrix of green agriculture to carry out reasonable clustering analysis based on the agricultural green development index and agricultural production benefit of each county and city. In the evaluation matrix, agricultural GDP per unit sown area was taken as a comparative index and the national average is the reference value. According to the numerical difference, it can be divided into four types including "High level-High benefits", "High levelHigh benefits", "Low level-High benefits" and "Low level-Low benefits" (Fig. 2).

\section{Results}

\section{Comparison of Agricultural Green Development Level between 2013 and 2018}

According to the established index system, this study calculates the weight of each evaluation index based on the entropy weight method and analytic hierarchy process, and obtains the final weight by using the weighted average method (Table 2). In 2018, the corresponding weight values of agricultural green production, green innovation, green eco-protection and green economy are respectively $0.2305,0.2505,0.1667$, 0.3523 . Combination of various indicators, G1, G2, G3, G4 and GDI are calculated by using Formula (3). The results are shown in Table 3 and Fig. 3.

As a whole, the comparison of comprehensive evaluation results between 2013 and 2018 illustrate that the agricultural green development level has been greatly improved in the past five years. The average value of agricultural green development index in Yili River Valley increased from 30.65 in 2013 to 36.99 in 2018, which mainly attributed to the improvement 


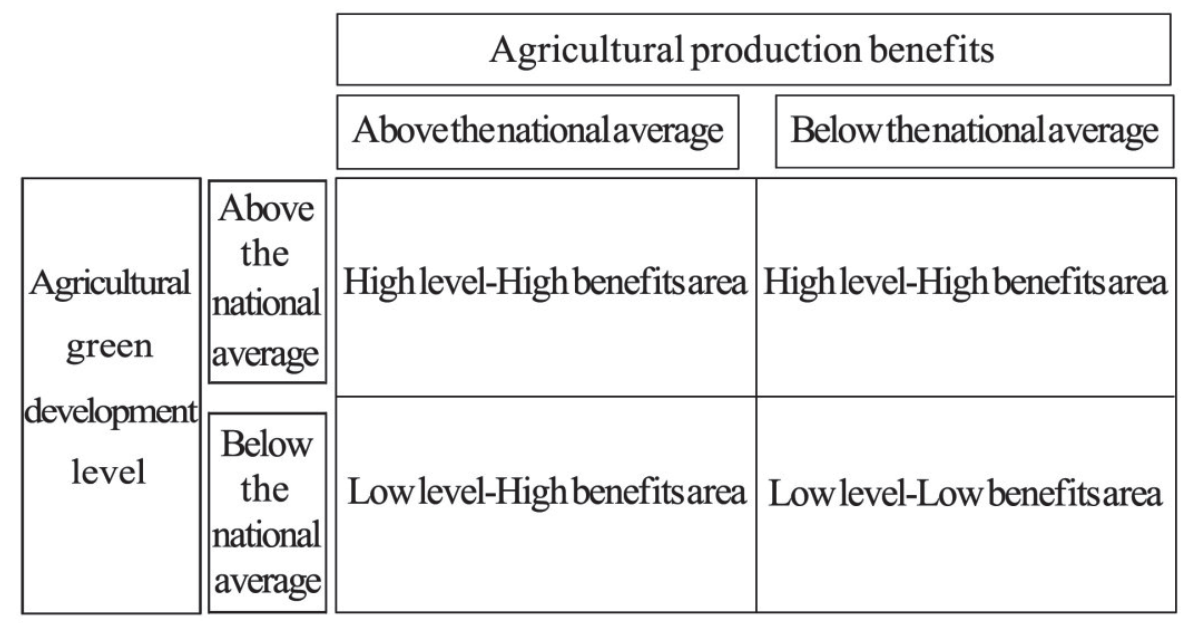

Fig. 2. The comprehensive evaluation matrix of green agriculture.

of agricultural production conditions and agricultural industrialization level. However, there is a large gap in the agricultural green development index between counties and cities, and that of most counties are lower than the national average (Table 3 ).
From the evaluation results of the second-level index, the index of both green production and green economy of each county and city has increased to some extent from 2013 to 2018, especially the agricultural production conditions of the counties of Yining, Huocheng and

Table 2. Weight of each level evaluation index based on analytic hierarchy process and entropy weight in 2013 and 2018.

\begin{tabular}{|c|c|c|c|c|c|c|c|}
\hline \multirow{2}{*}{ The second-level index } & \multirow{2}{*}{ Index level } & \multicolumn{3}{|c|}{2013} & \multicolumn{3}{|c|}{2018} \\
\hline & & $W_{\mathrm{AHP}}$ & $W_{\mathrm{j}}$ & $W$ & $W_{\mathrm{AHP}}$ & $W_{\mathrm{j}}$ & $W$ \\
\hline \multirow{5}{*}{ Green production (G1) } & $\mathrm{X} 1$ & 0.0108 & 0.0186 & 0.0147 & 0.0268 & 0.0156 & 0.0212 \\
\hline & $\mathrm{X} 2$ & 0.0173 & 0.0186 & 0.0179 & 0.0263 & 0.0155 & 0.0209 \\
\hline & $\mathrm{X} 3$ & 0.0101 & 0.0181 & 0.0141 & 0.0379 & 0.0156 & 0.0268 \\
\hline & $\mathrm{X} 4$ & 0.1203 & 0.1338 & 0.1271 & 0.0802 & 0.0810 & 0.0806 \\
\hline & $\mathrm{X} 5$ & 0.0589 & 0.0607 & 0.0598 & 0.0869 & 0.0751 & 0.0810 \\
\hline \multirow{5}{*}{ Green innovation (G2) } & X6 & 0.0814 & 0.0860 & 0.0837 & 0.1293 & 0.1337 & 0.1315 \\
\hline & $\mathrm{X} 7$ & 0.0509 & 0.1140 & 0.0825 & 0.0269 & 0.0373 & 0.0321 \\
\hline & $\mathrm{X} 8$ & 0.0328 & 0.0395 & 0.0362 & 0.0328 & 0.0354 & 0.0341 \\
\hline & X9 & 0.0283 & 0.0303 & 0.0293 & 0.0483 & 0.0231 & 0.0357 \\
\hline & $\mathrm{X} 10$ & 0.0169 & 0.0195 & 0.0182 & 0.0178 & 0.0163 & 0.0170 \\
\hline \multirow{5}{*}{ Green eco-protection (G3) } & $\mathrm{X} 11$ & 0.0202 & 0.0204 & 0.0203 & 0.0222 & 0.0214 & 0.0218 \\
\hline & $\mathrm{X} 12$ & 0.0713 & 0.0802 & 0.0757 & 0.0491 & 0.0439 & 0.0465 \\
\hline & $\mathrm{X} 13$ & 0.1306 & 0.1313 & 0.1310 & 0.0414 & 0.0595 & 0.0504 \\
\hline & $\mathrm{X} 14$ & 0.0509 & 0.0410 & 0.0460 & 0.0299 & 0.0284 & 0.0292 \\
\hline & $\mathrm{X} 15$ & 0.0599 & 0.0236 & 0.0418 & 0.0189 & 0.0186 & 0.0188 \\
\hline \multirow{5}{*}{ Green economy (G4) } & $\mathrm{X} 16$ & 0.0596 & 0.0481 & 0.0538 & 0.0376 & 0.0478 & 0.0427 \\
\hline & $\mathrm{X} 17$ & 0.0251 & 0.0183 & 0.0217 & 0.0114 & 0.0155 & 0.0134 \\
\hline & $\mathrm{X} 18$ & 0.0349 & 0.0203 & 0.0276 & 0.0151 & 0.0169 & 0.0160 \\
\hline & $\mathrm{X} 19$ & 0.0569 & 0.0263 & 0.0416 & 0.1948 & 0.2169 & 0.2059 \\
\hline & $\mathrm{X} 20$ & 0.0629 & 0.0513 & 0.0571 & 0.0664 & 0.0822 & 0.0743 \\
\hline
\end{tabular}


Table 3. Comparison of agricultural green development index of each county and city between 2013 and 2018.

\begin{tabular}{|c|c|c|c|c|c|c|c|c|}
\hline \multirow{2}{*}{ Counties/Cities } & \multicolumn{2}{|c|}{ Green production } & \multicolumn{2}{c|}{ Green innovation } & \multicolumn{2}{c|}{ Green eco-protection } & \multicolumn{2}{|c|}{ Green economy } \\
\cline { 2 - 10 } & 2013 & 2018 & 2013 & 2018 & 2013 & 2018 & 2013 & 2018 \\
\hline Yining City & 7.47 & 12.46 & 16.45 & 13.42 & 10.55 & 5.39 & 1.67 & 28.78 \\
\hline Yining County & 14.84 & 23.94 & 13.69 & 10.93 & 9.47 & 4.66 & 4.40 & 5.39 \\
\hline Chabuchaer County & 12.96 & 20.76 & 11.67 & 10.34 & 6.47 & 3.64 & 2.53 & 4.65 \\
\hline Huocheng County & 11.39 & 18.19 & 12.93 & 10.68 & 7.04 & 3.72 & 2.92 & 9.10 \\
\hline Gongliu County & 9.88 & 15.58 & 9.07 & 8.05 & 3.77 & 2.66 & 2.58 & 5.53 \\
\hline Xinyuan County & 10.62 & 16.84 & 13.71 & 10.21 & 4.69 & 2.74 & 3.97 & 6.97 \\
\hline Zhaosu County & 8.77 & 13.54 & 12.40 & 9.48 & 2.86 & 1.87 & 2.26 & 4.68 \\
\hline Tekesi County & 8.10 & 12.43 & 7.25 & 2.31 & 1.50 & 1.37 & 2.33 & 6.07 \\
\hline Nileke County & 8.54 & 13.17 & 13.31 & 6.29 & 1.22 & 1.20 & 2.56 & 5.86 \\
\hline
\end{tabular}

Chabuchaer greatly improved, and ecological leisure agriculture the city of Yining and Huocheng developed rapidly. In 2018, the green economy index is up to

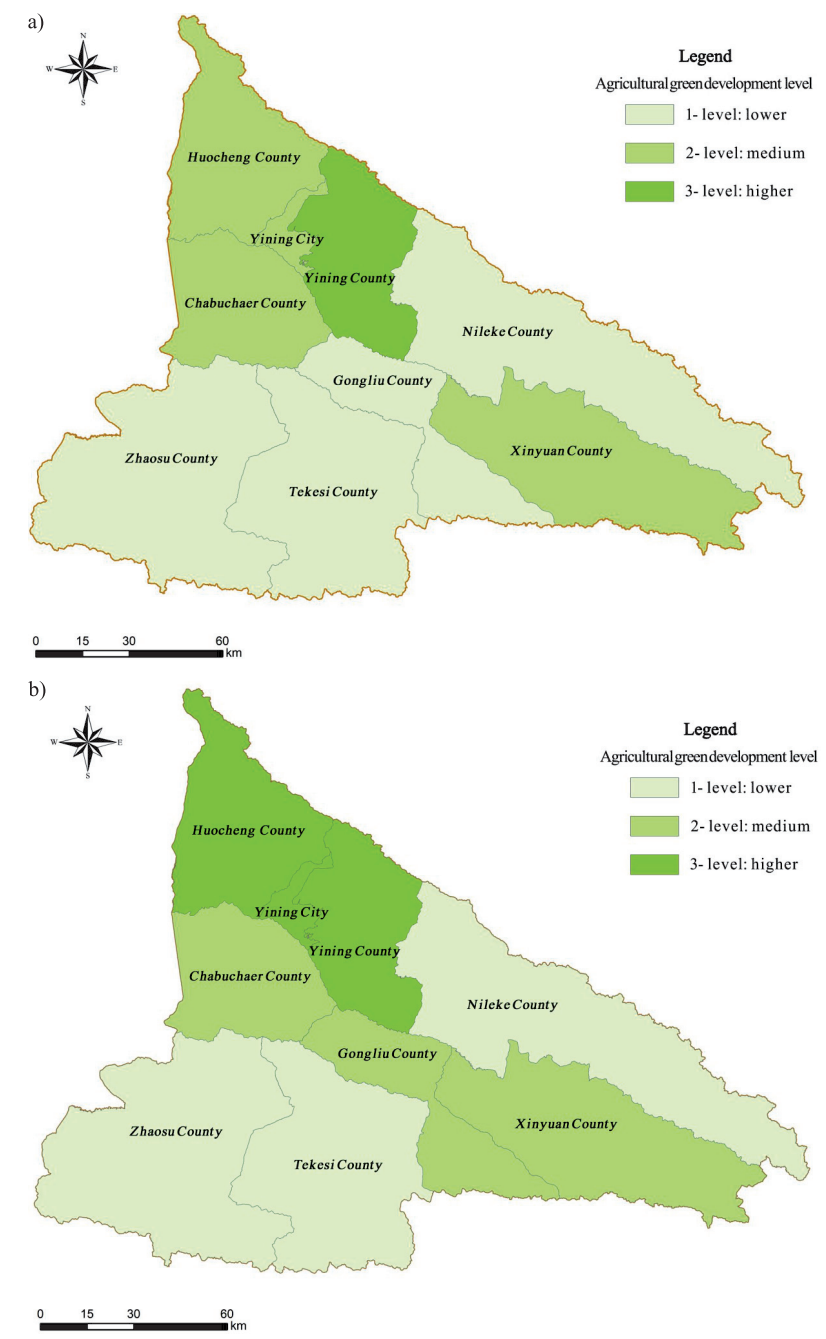

Fig. 3. Agricultural green development level of Yili River Valley in: a) 2013 and b) 2018 .
28.78. However, the index of both green innovation and green eco-protection decreased. For the counties of Nileke, Tekesi, the agricultural science and technology innovation level is not high and lack of new driving force for development. For Yili River Valley, the rapid development of agriculture has exerted severe stress on the fragile ecological environment in recent years, especially Yining, leading to a low level of green ecoprotection as a whole. Therefore, the supply capacity of green and high-quality agricultural products needs to be further improved.

\section{Spatial Distribution Characteristics of Agricultural Green Development}

To better depict the spatial distribution characteristics and its changing trend of agricultural green development from 2013 to 2018, the paper uses cluster analysis based on the GIS platform to divide the comprehensive index into three types of lower, medium and higher. The evaluation results are shown in Fig. 4. From the perspective of spatial distribution, the green development level in the western agricultural area of Yili Valley is higher than that in the eastern animal husbandry area, and there are great differences between counties and cities. In 2018, the agricultural green development index of Yining city is as high as 60.06, while that of Tekesi is only 22.18; From the perspective of spatial change trend, the agricultural green development level is constantly improving and the spatial heterogeneity is becoming more and more obvious. The overall level of agricultural green development in all counties and cities has been improved from 2013 to 2018. There is also an increase in the number of counties and cities with a high level of agricultural green development, which include Yining city, the counties of Yining and Huocheng, while the agricultural green development of most counties are still in the low- and medium-level. 


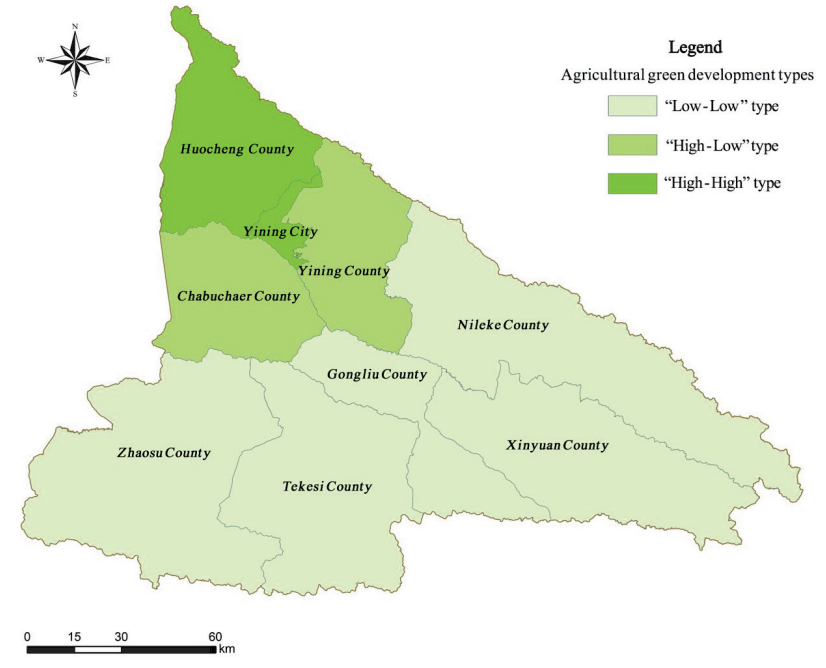

Fig. 4. Agricultural green development type of the counties and cities in Yili River Valley.

\section{Spatial Characteristics of Agricultural Green Development Type}

In order to further analyze the relationship between agricultural green development level and agricultural production benefits of different counties and cities in Yili River Valley, according to Table 4, this paper uses the comprehensive evaluation matrix of green agriculture for cluster analysis. Fig. 4 clearly shows that there are only three types of "High-High", "High-Low" and "Low-Low", respectively representing the areas of "High level-High benefits", "High level-Low benefits" and "Low level-Low benefits". The spatial difference of agricultural green development level and agricultural economic benefits between counties and cities in
Yili Valley is significant, presenting an unbalanced development state, which decreased from northwest to southeast on the whole.

"High-High " type are concentrated on Yining city and Huocheng county. The agricultural green development level and agricultural production efficiency of Yining city are higher, mainly because of the high application efficiency of pesticides and fertilizers, and the pesticide consumption of agricultural GDP per ten thousand yuan is less than that of $1 \mathrm{~kg}$. What's more, leisure agriculture and rural tourism have developed rapidly in recent years, with an output value of 11.37 billion yuan in 2018. The utilization and popularization rate of agricultural water-saving irrigation in Huocheng are relatively high, which ensures that its agricultural economic, environmental and social benefits have been greatly improved. At present, the popularization rate of agricultural water-saving irrigation in Huocheng is over $80 \%$; "High-Low" type is mainly distributed in Chabuchaer and Yining. The common cause of the high level of green agriculture development are low intensity of pesticide application, high utilization rate of water-saving irrigation and high level of mechanization. However, due to the low level of agricultural development, together with the single agricultural production structure, the agricultural output benefits are poor; The areas of "Low-Low" include Zhaosu, Gongliu, Xinyuan, Tekesi and Nileke, which are dominated by modern animal husbandry. Mainly due to the lower use efficiency of chemical fertilizers and pesticides, the lower penetration rate of water-saving irrigation and the lower comprehensive utilization rate of aquaculture waste, the overall level of agricultural green development in these counties is not high. Low agricultural production efficiency is mainly restricted by two factors, one is the low level of industrialization

Table 4. Agricultural green development level and production benefits of each county and city in Yili Valley between 2013 and 2018.

\begin{tabular}{|c|c|c|c|c|c|c|}
\hline \multirow{2}{*}{ Counties/Cities } & \multicolumn{2}{|c|}{$\begin{array}{c}\text { Development level of green } \\
\text { agriculture in } 2013\end{array}$} & $\begin{array}{c}\text { Agricultural } \\
\text { production efficien- } \\
\text { cy in 2013 }\end{array}$ & $\begin{array}{c}\text { Development level of green } \\
\text { agriculture in 2018 }\end{array}$ & $\begin{array}{c}\text { Agricultural } \\
\text { production efficiency } \\
\text { in 2018 }\end{array}$ \\
\cline { 2 - 7 } & Value & Ranking & Yuan/hm ${ }^{2}$ & Value & Ranking & Yuan/hm ${ }^{2}$ \\
\hline Yining City & 36.13 & 2 & 35920.72 & 60.06 & 1 & 46593.50 \\
\hline Yining County & 42.40 & 1 & 23882.79 & 44.91 & 2 & 20409.84 \\
\hline Chabuchaer County & 33.64 & 4 & 19460.63 & 39.39 & 4 & 22060.22 \\
\hline Huocheng County & 34.29 & 3 & 31204.40 & 41.69 & 3 & 44431.71 \\
\hline Gongliu County & 25.30 & 8 & 18523.90 & 31.81 & 6 & 17515.79 \\
\hline Xinyuan County & 32.99 & 5 & 20502.58 & 36.75 & 5 & 21797.36 \\
\hline Zhaosu County & 26.28 & 6 & 13422.16 & 29.57 & 7 & 18147.21 \\
\hline Tekesi County & 19.18 & 9 & 16294.55 & 22.18 & 9 & 19024.30 \\
\hline Nileke County & 25.64 & 7 & 15852.94 & 26.51 & 8 & 19432.51 \\
\hline The national average & 33.96 & - & 21876.85 & 41.16 & - & 23480.37 \\
\hline
\end{tabular}


and the lack of agricultural characteristics, the other is the traditional mode of agricultural production and poor agricultural production conditions.

\section{Discussion}

The results show that the spatial heterogeneity is becoming more and more obvious while agricultural green development of most counties is still in low- and medium-level, mainly because of the production mode with high input of chemicals and high consumption of resources, unreasonable regional layout of agricultural products, lack of the distinctive brand advantages, and the hidden dangers in quality and safety. Therefore, under the development trend of featured and green food consumption market at home and abroad, it is an inevitable choice to promote green, innovative and integrated development for agricultural transformation and upgrading. Aiming at the bottleneck problems of Yili River Valley, this paper focuses on protecting the ecological chain and enhancing the value-added chain as main developing routes, and puts forward the green empowerment paths of agro-ecosystem symbiosis which include promoting differential development, improving agricultural habitat environment, and enhancing the agroecological value, which can solve the long-term contradiction between agriculture and ecology, reshape the eco-economy system of agro-ecological symbiosis, and improve the agricultural green development level in general (Fig. 5).
Following the Main Function Orientation and Promoting Differential Development

According to the main function orientation of the restricted development areas, for Yili River Valley, it should control the agricultural development scale reasonably and reduce the pressure of water and soil resources to better protect its agricultural productivity and ecological product productivity. Based on the unique ecological and resource endowment advantages, it can develop the characteristic and differentiated spatial layout of " two regions, five bases". Two regions refer to the leading development area of green agricultural products including Yining, Huocheng and Chabuchaer, and that of green livestock products including Xinyuan, Gongliu, Zhaosu, Tekesi and Nileke; Five bases refer to vegetable production bases with Yining city as center and the counties of Yining, Huocheng and Chabuchaer as supplementary, lavender spice base with Huocheng as the center, bee industry base centered on the counties of Nileke, Xinyuan and Gongliu, potato industry base with Zhaosu as the center, horse industry base centered on Yili stud farm and Zhaosu horse farm.

\section{Pushing Green Production Mode and Improving Agricultural Habitat Environment}

In Yili River Valley, there are 2/3 medium-low yield fields. Therefore, it is necessary to change the agricultural development mode which mainly depends on resource consumption, and take the road of modern agricultural development with high output efficiency,

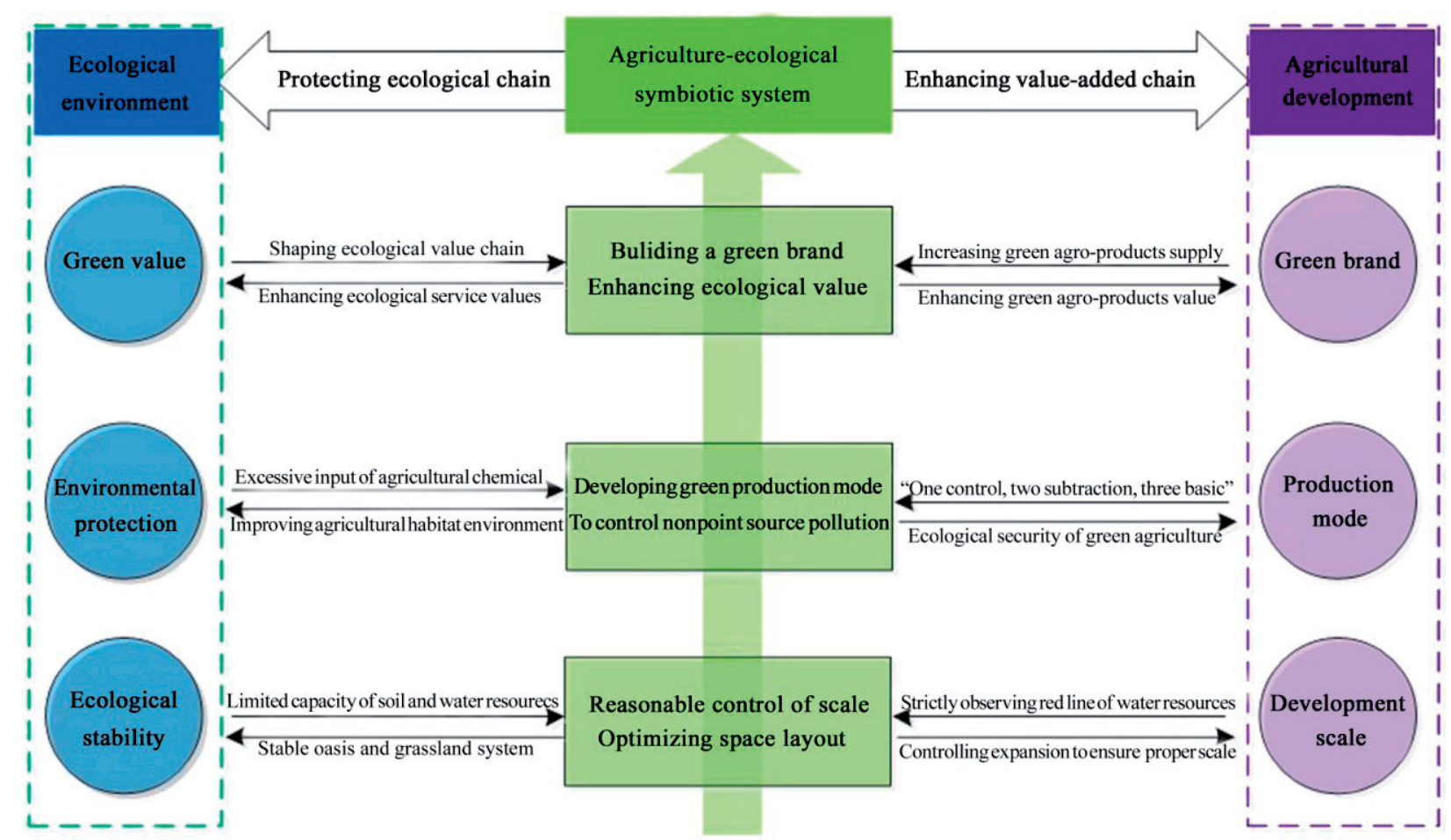

Fig. 5. The optimized path for agricultural green development of Yili River Valley. 
product safety, resource saving, and environmentfriendly actions. We should vigorously develop watersaving agriculture, strengthen the construction of water-saving irrigation projects, and popularize technologies such as high-efficiency water-saving and the integration of water and fertilizer. Firstly, the total amount of agricultural water use should be controlled by strengthening the monitoring and management of irrigation water quality, to ensure that agricultural irrigation water meets the water quality standards for farmland irrigation. Secondly, the focus should be on promote the application of new integrated technologies of farmyard fertilizer, biological fertilizer as well as the integrated control of crop diseases and pests to achieve zero growth. Finally, for the modern pastoral areas, it's a good choice to develop farming communities to separate human beings from livestock, and standardize and guide livestock farms to make good use of the resources of breeding wastes. For the modern agricultural areas, it should deeply develop straw resource utilization and effective recovery and treatment of waste agricultural film.

\section{Building the Agricultural Green Brand and Enhancing the Ecological Value}

According to the general trend of agricultural brand development, for Yili River Valley, it should mainly strengthen the certification management, cultivate a number of well-known, high reputation of green quality brands, and create the first-class quality of green products in an all-round way to enhance the competitiveness of green products in the market. In addition, promoting intelligent supervision of the quality and safety of agricultural products ensures that all certified green, organic and geographically marked products can be traced back to the internet. In addition, the supply of green and high-quality agricultural products we should change the situation of individual households operating in a decentralized manner, and make large-scale agricultural operations, focusing on family farms, cooperatives and leading enterprises around the key industries of forestry, fruit and animal husbandry. What's more, "Internet +" should be used to establish a new production system and supply chain system led by branding, so that farmers can become participants and benefit sharers of brand creation to truly realize income increase.

\section{Conclusions}

From a new perspective of the agroecosystem symbiosis, this study made a dynamic comparative analysis of agricultural green development level between 2013 and 2018 in Yili River Valley by setting up a multi-dimensional evaluation index system, and explored spatial distribution characteristics and existing contradictions to find new paths for agricultural green development. The main conclusions are as follows:

(1) The average level of green agricultural development in Yili River Valley increased from 30.65 in 2013 to 36.99 in 2018, which scientifically illustrated that ecological economy and green innovation play greats roles in the process of agricultural green development, and the supply capacity of green and high-quality agricultural products needs to be further improved. From the perspective of spatial characteristics, the green development level in western agricultural area is higher than that in eastern animal husbandry area with the gap between counties and cities further expanding, which means the spatial heterogeneity is becoming more and more obvious.

(2) By clustering analysis with the comprehensive evaluation matrix of green agriculture, we found that there was a nonproportional relationship between agricultural green development level and agricultural production benefits in Yili River Valley, and it showed an unbalanced state which decreases from northwest to southeast in space, mainly because of the production mode with high input of chemicals and high consumption of resources, lack of characteristics and brand advantages of agricultural products themselves, and the hidden dangers of the quality and safety of agricultural products. Therefore, it is urgent to find a breakthrough from the path of agricultural development and promote green agricultural transformation and upgrading.

(3) Aiming at the existing problems, according to the unique ecological and resource advantages of Yili River Valley, we proposed the green empowerment path of agro-ecosystem symbiosis based on protecting ecological chain and promoting value-added chain and practical countermeasures and suggestions. With the improvement of agricultural green development level. In the future, it can foster new driving forces to develop smart agriculture by building the new pattern of agricultural development with long chain and multiformat. This study has broad prospects for promotion and application in similar restricted development area, and also offer valuable assistance for policy-maker and practitioners in underdeveloped countries.

\section{Acknowledgements}

This work was financed by the Natural Science Foundation of Jiangsu province in China (BK20181105), the autonomous deployment project of Nanjing Institute of Geography and Limnology, CAS (NIGLAS2017QD12), the Strategic Priority Research Program A of the Chinese Academy of Sciences (XDA20010301) and National Key R\&D Program of China, No.2018YFD1100101. 


\section{Conflict of Interest}

The authors declare no conflict of interest.

\section{References}

1. XU L.M., WANG H., GUO F.Y. Measurement on green development efficiency of the restricted development zones in Shandong Province. Resource Development \& Market, $\mathbf{8}, 845,2020$.

2. LU Y.L., NORSE D., POWLSON D. Agriculture green development in China and the UK: common objectives and converging policy pathways. Frontiers of Agricultural Science and Engineering, 7 (01), 101, 2020.

3. TIAN Y., ZHANG J.B. Study on regional differences and genesis in development level of green agriculture in China. Research of Agricultural Modernization, 34 (01), 81, 2013.

4. LI P., TONG L.J., FAN W.G., GUO Y.H. Evolution of Green Development Pattern and Identification of Obstacles in the Restricted Development Zones of Jilin Province. Scientia Geographica Sinica, 40 (05), 736, 2020.

5. KASZTELAN A. Green growth, green economy and sustainable development: terminological and relational discourse. Prague Economic Papers, 26 (04), 487, 2017.

6. MATHAI M.V., OLIVEIRA J.A.P.D., DALE G. The rise and flaws of green growth. APN Science Bulletin, 8 (01), 60, 2018.

7. FAN W.G. Research on green development of restricted development areas. Northeast Normal University, 2019.

8. GUO Y. H., TONG L.J., MEI L. The level of green development and obstacle factors in limited development ecological zone of Jilin Province. Acta Ecologica Sinica, 40 (07), 2466, 2020.

9. PAN W., PAN W.L., HU C., TU H.T., ZHAO C., YU D.Y., XIONG J.W. ZHENG G.W. Assessing the green economy in China: an improved framework. Journal of Cleaner Production, 209 (02), 686, 2018.

10. LILIIA M., PETR S., SERGEY E., MARIA B. Improvement of Russian energy efficiency strategy within the framework of 'green economy' concept (based on the analysis of experience of foreign countries). Energy Policy, 125 (02), 480, 2019.

11. AMINI S., ROHANI A., AGHKHANI M.H., ABBASPOUR-FARD M.H., ASGHARIPOUR M.R. Assessment of land suitability and agricultural production sustainability using a combined approach (FuzzyAHP-GIS): a case study of Mazandaran province, Iran. Information Processing in Agriculture, 7 (03), 2, 2019.

12. KANTER D.R., MUSUMBA M., WOOD S.L.R., PALM C., ANTLE J., BALVANERA P., DALE V.H., HAVLIK P., KLINE K.L., SCHOLES R.J., THORNTON P., TITTONELL P., ANDELMAN S. Evaluating agricultural trade-offs in the age of sustainable development. Agricultural Systems, 163, 74, 2018.

13. QUINTERO-ANGEL M., GONZALEZ-ACEVEDO A. Tendencies and challenges for the assessment of agricultural sustainability. Agriculture, Ecosystems \& Environment, 254, 278, 2018.

14. XIE S.J., KUANG Y.Q., HUANG N.S., ZHAO X.K. Construction of low carbon agriculture evaluation index system and evaluation on Guangdong province. Journal of Ecological Environment, 6, 920, 2013.
15. LIU T. Evaluation on low carbon agriculture development in Hunan province. Central South University of Forestry and Technology, 2018.

16. LIU Y.Y., FENG Z.C., LI P., DING Y. M. Performance and Regional Difference in Chinese Ecological Agriculture. Economic Geography, 3, 27, 2014.

17. GONG Q.W., LI X.M. Construction and measurement of agricultural green development index: 2005-2018. Reform, 1, 135, 2020.

18. ZHANG N.M., ZHANG L., ZHAO H., HAN Y.C., DUAN Y.H. Construction and application of agricultural green development evaluation index system. Ecological Economy, 11, 23, 2018.

19. ZHAO W.F., ZHAENG Q., ZHANG D.H. Study on dynamic prediction and path of green development level of agricultural in Anhui Province. Journal of China Agricultural Resources and Regional Planning, 39 (10), 53, 2018.

20. KOOHAFKAN P., ALTIERI M.A., GIMENEZ E.H. Green Agriculture: foundations for biodiverse, resilient and productive agricultural systems. International Journal of Agricultural Sustainability, 10 (01), 63, 2012.

21. JIANG Y.Y. Level of development of Hunan agricultural green measure and development path selection research. Hunan Agricultural University, 2018.

22. LIU L.C., LIU S.Z. Impact of country-of-origin image of Guizhou province on brand trust of green agricultural products. Ecological Economy, 15 (01), 21, 2019.

23. HUANG Z.L. Analysis on the path of agricultural green development in Nanyang. Rural economy and technology, 24, 22, 2016.

24. AL-MANSOUR F., JEJCIC V. A model calculation of the carbon footprint of agricultural products: the case of Slovenia. Energy, 136 (10), 7, 2017.

25. BORSATO E., TAROLLI P., MARINELLO F. Sustainable patterns of main agricultural products combining different footprint parameters. Journal of Cleaner Production, 179 (04), 357, 2018.

26. NUTTAVUTHISIT K., THOGERSEN J. The importance of consumer trust for the emergence of a market for green products: the case of organic food. Journal of Business Ethics, 140 (02), 10, 2017.

27. TESTA F., SARTI S., FREY M. Are green consumers really green? Exploring the factors behind the actual consumption of organic food products. Business Strategy and the Environment, 28 (02), 330, 2019.

28. TADESSE S. Financial architecture and economic performance: international evidence. Journal of Financial Intermediation, 11 (04), 430, 2009.

29. HARMAN G. E. Overview of mechanisms and uses of Trichoderma spp.. Phytopathology, 96 (02), 190, 2014.

30. XU B.W., WANG H.P., LIN G.H. Application of policy instruments for green growth of agriculture in Europe and America and its enlightenment. Journal of Fujian Agriculture and Forestry University (Philosophy and Social Sciences), 22 (01), 16, 2019.

31. COMPAGNONE C., PETIT S., Lémery B. A new role of mediator for extension services: a challenge for the Chambers of agriculture in France. Journal of extension systems, 24 (02), 16, 2018.

32. JU X.H., XUE Y.H., XI B., JIN T., XU Z.Y., GAO S.B. Establishing an agro-ecological compensation mechanism to promote agricultural green development in China. Journal of Resources and Ecology, 9 (04), 429, 2018. 
33. LIU X.R., HAO Z.H., LI L. Study on the current status and countermeasures of green agriculture in Handan. Journal of Handan polytechnic College, 31 (03), 48, 2018.

34. ZHENG W.W., SHEN G.Y. Research on the current situation, problems and countermeasures of agricultural green development in Jiangsu province Jiangsu. Agricultural Sciences, 7, 3, 2018.

35. LONG F.Y., WANG C. The current status and strategy of agricultural green development in Jiangsu Province. IOP Conference Series: Earth and Environmental Science, 267 (05), 4, 2019.

36. SUN W.L., WANG R.B., JIANG Q., HUANG S.N. Study on connotation and evaluation of the agricultural green development. Chinese journal of agricultural resources and regional planning, 40 (04), 16, 2019.

37. SUN Y.S. Research on the industry green development and spatial organization of restricted development zone in Jilin Province. University of Chinese Academy of Science, 2018.

38. ZHU Y.Y., YU B., ZENG J.X., HAN Y. Spatial optimization from three spaces of production, living and ecology in National Restricted Zones - a case study of Wufeng County in Hubei Province. Economic Geography, 35(04), 28, 2015.

39. GUO Y.H. The level of green development and pathway in restricted area - a case study of the key ecological function area in Jilin Province. Northeast Normal University, 2018.
40. WANG M.Q., LU Y.L. The study on eco-compensation in restricted development zones under the framework of the main functional area. Advanced Materials Research, 962, 2145, 2014.

41. ZHAO X.Y., LIU J.H., WANG W.J., LAN H.X., MA P.Y., DU Y.X. Livelihood sustainability and livelihood intervention of out-of-poverty farming households in poor mountainous areas: a case of Longnan mountainous area. 39 (06), 983, 2020.

42. ZHU L.J. County functional division in the important ecofunction areas: a case study in Guangze, Fujian Province. Fujian Normal University, 2016.

43. WANG G.L., YANG D.G., XIA F.Q., ZHONG R.S., XIONG C.H. Three types of spatial function zoning in Key Ecological Function Areas based on ecological and economic coordinated development: A case study of Tacheng Basin, China. Chinese geography science, 29 (04), 696, 2019.

44. MI N., YANG M.L., FAN X.G., MI W.B., LI T.S., WANG T.Y. Theory and application of the main functional subdivision of limited development ecological zones. Acta Ecologica Sinica, 36 (16), 5060, 2016. 